\title{
ESTUDIOS DE VISITANTES A MUSEOS
}

VISITOR STUDIES IN MUSEUMS

Volumen 11, Número 2

pp. 1-37

Este número se publicó el 30 de agosto de 2011

Keilyn Rodríguez Sánchez

La revista está indexada en los directorios:

LATINDEX, REDALYC, IRESIE, CLASE, DIALNET, DOAJ, E-REVIST@S,

La revista está incluida en los sitios:

REDIE, RINACE, OEI, MAESTROTECA, PREAL, HUASCARAN, $\underline{\text { CLASCO }}$ 


\title{
ESTUDIOS DE VISITANTES A MUSEOS
}

VISITOR STUDIES IN MUSEUMS

Keilyn Rodríguez Sánchez ${ }^{1}$

\begin{abstract}
Resumen $^{1}$ : Este artículo ofrece un estudio bibliográfico en torno a las investigaciones sobre la relación entre la museografía y sus visitantes. El objetivo central de este documento consiste en elaborar una clasificación de esos estudios en programas de investigación de manera que sirva de punto de partida para la construcción de una pedagogía del Museo. Para este fin, se utiliza la propuesta de Schulman, sobre tipificación de estudios en programas de investigación $y$, al respecto, se plantean cuatro tipos: investigaciones centradas en lo museográfico, investigaciones centradas en el comportamiento museal, investigaciones centradas en la interacción dispositivo-visitantes y las investigaciones centradas en la evaluación museográfica. Se concluye que los resultados de investigación de estos programas, junto con el conocimiento de las técnicas de diseño y a la teoría educativa, serían la base central de un planteamiento sobre pedagogía museológica.
\end{abstract}

Palabras clave: MUSEOGRAFÍA, ESTUDIOS DE VISITANTES/ESTUDIOS DE AUDIENCIA, PEDAGOGÍA MUSEOLÓGICA.

Abstract: This article is a bibliographical research study of museography and the relationship of visitors to them. The main objective of this paper is to develop a classification system of these studies of research programs which serve as a starting point for systematizing the pedagogics of the museum. The author's fourfold typology of research programs builds on Schulman's (1989) program research concept: museography centered research, museum behavior centered research, museum interaction (visitorexhibition) centered research, and museum evaluation centered research. The article reaches the conclusion that the research findings of these programs along with knowledge of design techniques and educational theory will serve as the primary basis for a Museology pedagogy proposal.

Keywords: MUSEOGRAPHY, VISITOR STUDIES/AUDIENCE RESEARCH, MUSEOLOGY PEDAGOGICAL.

\footnotetext{
${ }^{1}$ Doctorado en Educación, una licenciatura en Antropología Social y otra en Ciencias de la Educación con énfasis en Administración de Programas de Educación no Formal, todos de la Universidad de Costa Rica. Ha trabajado en el ámbito de los museos desde el año 1992. Es funcionaria del Ministerio de Cultura y Juventud, destacada al Centro Costarricense de Ciencia y Cultura (sede del Museo de los Niños). Actualmente labora para la Dirección Ejecutiva del Complejo Cultural en Conceptuación de Proyectos.
}

Dirección electrónica: krodriguez@museocr.org, keilynrosa@gmail.com

Artículo recibido: $1^{\circ}$ de abril, 2011

Aprobado: 28 de julio, 2011

\footnotetext{
1 Un agradecimiento a quienes facilitaron estudios de público que permitieron esta investigación, entre ellos: museos costarricenses y latinoamericanos, al Smithsonian Institution y al PHD. Kevin Crowley. Además, gracias al Comité de Tesis Doctoral (Dr. Domingo Campos -director-, Dr. Rolando Pérez y Dr. Jorge Murillo), ya que este documento es un fruto de ese Trabajo Final de Graduación.
} 


\section{Introducción}

El presente artículo tiene como objetivo central ofrecer una propuesta de clasificación de la investigación que evidencie procesos educativos entre las personas visitantes de una exhibición museográfica, con el propósito de que sirva de punto de partida para la construcción de una pedagogía del Museo en el ámbito de las exhibiciones. Los reportes de investigación seleccionados para este trabajo corresponden a los llamados "estudios de público o audiencia" (Visitor Studies, Audience Research) en museos.

Es importante aclarar que la autora utiliza el estado de la investigación presentado en su tesis doctoral (Rodríguez, 2008) como referencia para este artículo, al que le realiza modificaciones sustanciales especialmente en la clasificación de los programas de investigación, con base en estudios recientes o recopilados en los últimos años, los cuales ha registrado hasta el presente con ayuda del marcador social colaborativo en línea Delicious.com², propiedad de Yahoo! Inc@).

Se ofrece, para el ámbito internacional, una clasificación de estudios de los últimos 20 años; al respecto, Schulman (1989) propone el concepto de programas de investigación estableciendo que ellos se pueden identificar según lo que interesa ser estudiado, o sea, el objeto de investigación, y una serie de núcleos centrales de ideas asociadas a las explicaciones sobre ese objeto de estudio. Un programa puede incluir diferentes enfoques teóricos y metodológicos, siempre y cuando se puedan clasificar mediante un interés de investigación, y también puede incluir el núcleo central de supuestos o conceptos teóricos explicativos de la realidad de interés.

La delimitación de los estudios a los últimos 20 años, se realiza con base en los aportes de la experta en historia de la museología María Jesús Bolaños (2006), quien determina que en estos años el Museo ha tenido que hacer frente a exigencias intelectuales de la vida contemporánea post industrial y una de las más interesantes exigencias es la forma de concebir la presentación de los objetos y las obras de arte, lo cual supone un cambio en la expresión del modo en que los seres humanos establecen sus relaciones con el saber.

El conocimiento de esas nuevas formas de relación será el eje conceptual para una construcción de la pedagogía del Museo y, por lo tanto, para la delimitación de los estudios por analizar.

2 Puede consultarse parte de esta organización de información en http://www.delicious.com/keilynrosa 


\section{Delimitación preliminar}

Este artículo constituye un aporte a la museología desde una perspectiva educativa. La museología es una ciencia que abarca el estudio teórico y filosófico de lo que es un Museo y su gestión (Rico, 2006). La educación en Museos es uno de sus temas centrales, y aunque ha tomado un largo camino comprender las implicaciones de dicho tema, en el transcurso del tiempo se ha ido aclarando gracias a la contribución de la investigación en museos, según se podrá notar en la lectura de este documento.

Como bien sabemos, los museos han sido definidos como instituciones sin fines de lucro que se dedican a colectar objetos sobre un tema de interés, investigar sobre dichas colecciones y a educar y a divulgar el conocimiento de las mismas mediante las salas de exhibición y los programas educativos.

En este sentido, una línea de investigación ha sido forjada para comprender esa relación entre las personas visitantes y las exhibiciones. Esta línea de interés académico ha sido: estudios de visitantes en museos o estudios de audiencia (Visitor Studies o Audience Research). Es este grupo de investigaciones las que son el objeto de estudio de esta investigación.

Al respecto, los estudios de visitantes de Museos constituyen el proceso sistemático de construcción del conocimiento de y sobre visitantes de exhibiciones museográficas actuales y potenciales, con el propósito de incrementar y utilizar dicho conocimiento en la planificación y en la ejecución de actividades relacionadas con ellos (AMM, 1991).

Estas investigaciones pueden ser vinculadas con: temáticas de mercado, elaboración de exhibiciones, programas educativos, señalización y servicios al público en general, ya que proveen información sobre la mejor manera de exponer una temática o problema, sobre las características de las personas y de los grupos sociales que participan de las exhibiciones y sobre las formas y los resultados de ese encuentro visitante(s)-exhibiciones.

Ahora bien, no se incluirán en este documento investigaciones sobre estudios de mercado ni trabajos específicos sobre discusiones del método que ya se dan en otros espacios académicos. Solo estudios vinculados con aspectos educativos del Museo propiamente, o sea, las investigaciones educativas en el contexto de una exhibición ${ }^{3}$, ya sea por su disposición museográfica (entendida como educación no formal), por su uso o por las posibilidades de

3 También se excluyen los estudios sobre museos virtuales por la naturaleza de los mismos. 
interacción que las personas visitantes construyen en su visita (entendida como educación informal).

También, resulta necesario definir el concepto de museografía. La entendemos como la disciplina técnica que conlleva la aplicación de los lineamientos teórico-filosóficos de la museología. A diferentes corrientes museológicas, diferentes técnicas expositivas. Para los anglosajones, por ejemplo, la museografía es sinónimo de expografía, y trata de los criterios utilizados para establecer la relación de la obra/objeto/dispositivo (elemento museográfico) con el espacio (arquitectura, orden en la secuencia de objetos, relación de las piezas entre sí en el espacio, iluminación, entre otros similares) y la función que debe cumplir con el público (Rico, 2006).

La museografía concreta un despliegue de tecnología educativa y cuando sucede que desde una disposición expográfica con unos objetivos pedagógicos es montada una exhibición, hablamos de museografía didáctica.

Ahora bien, tradicionalmente, en el ámbito de los Museos, lo educativo ha sido referido a los programas o proyectos que elabora un departamento de educación como complemento de las exhibiciones que el Museo dispone (Pastor, 2004).

Entre ellos están los campamentos (Luján y Rodríguez, 2011), los talleres (Rodríguez y Vargas, 2009), las charlas y las conferencias, los festivales, los concursos y los certámenes de diferentes temas y técnicas plásticas y literarias, entre otros, dirigidos a un público variado (Pastor, 2004).

Un intento por establecer la didáctica del Museo lo ofrece García (1988). Sin embargo, no aborda a la museografía en su diseño como parte de esa didáctica, limitándose a los programas de educación no formal y a las formas de aprovechamiento educativo de las exhibiciones.

Por su parte, Piñero (2009) señala que frecuentemente lo pedagógico es dejado de lado cuando surge un planteamiento museográfico. Esto resulta irónico, pues la intensión de una exhibición es cumplir con una función educativa del Museo. Si bien existe una pedagogía cultural al respecto (Poll y Asensio, 1997), es necesario un planteamiento fundamentado científicamente.

Aunado a lo anterior, están las exhibiciones museográficas que son el elemento central del Museo, y aunque las clasificamos como medio para cumplir la función educativa de esta institución, aún nos falta comprender y sistematizar las implicaciones de los procesos gestados entre visitantes-exhibiciones y el papel pedagógico de esos diseños. 
Los objetos y las formas en que son dispuestos en una sala, para transmitir un mensaje, además de las posibilidades de interacción, que desde su diseño son concebidos para orientar el pensamiento de visitantes, la interacción con el objeto y entre los visitantes, son las que contribuyen a la co-construcción del conocimiento compartido y, por eso, constituyen orientaciones pedagógicas.

Así, la pedagogía museográfica no está claramente sistematizada y son los resultados de investigaciones en este campo los que nos pueden dar una luz que permita una propuesta en este sentido.

Con todo, existen algunas propuestas iniciales en este campo, pero nada consolidado, pues, por un lado, la propuesta de Zimerman y cols. (2008) cuenta con aportes sobre los fines didácticos de las exposiciones, pero no incorpora suficientes resultados de investigación ni las interacciones sociales en las exposiciones. Otras propuestas van de la teoría de la educación hacia los museos (Hein, 2004; Hein, 2006; Hernández y Rubio, 2009). Falta concretar una propuesta teórica que integre la teoría educativa, los resultados de investigación en museos y los criterios técnicos de diseño. Al respecto, Alfageme y Marín (2006) indican que es necesario sistematizar lo pedagógico para potenciar la función educativa del Museo.

En este sentido, en el espacio museal estaría presente una práctica pedagógica (Daniels, 2003), pues es un contexto social donde son producidos y reproducidos significados culturales guiados por unas formas de participación que ofrecen las exhibiciones museográficas, y que sirven de referencia para las interacciones humanas.

Entonces, ¿cuáles son los mejores diseños para lograr los objetivos del Museo? ¿Cuál es la mejor forma de ordenarlos en el espacio para que las personas atiendan a la mayoría posible? ¿Utiliza la gente los objetos de la forma en que se predeterminó? ¿Qué sucede en ese encuentro visitante-objeto? Las respuestas a estas preguntas y otras son respondidas en estudios de visitantes y son las que permiten mejorar la museografía didáctica. Así las cosas, el espacio museográfico cuenta con varias características que identifican su dimensión educativa; por ejemplo:

- El Museo no es un ambiente natural, es un ambiente artificial en tanto que está adaptado y diseñado pedagógicamente por el ser humano (Ramsey, 1971).

- Es un espacio físico estructurado en micro espacios o exhibiciones. Esos micro espacios cuentan con objetos virtuales, en tanto que fueron diseñados para ser parte de una 
puesta en escena educativa con unos significados concretos desde el punto de vista del museógrafo, pero los visitantes co-interpretan tales objetos desde múltiples perspectivas y referentes.

- Los significados de los objetos co-construidos en la interacción con el espacio museográfico son parte de la dinámica de estructuración de campos semánticos del conocimiento compartido que no inician ni terminan en el Museo, por lo tanto, son virtuales.

- El espacio es la estructura subyacente en el Museo, el encuentro entre los visitantes y dicho espacio; el evento constituye un problema educativo central para la institución en sus fines educativos (Ramsey, 1971).

- El evento es lo emergente, es plasticidad puesto que es una síntesis del proceso que se da del encuentro entre los visitantes y el espacio museal, lo cual ocurre a cada instante y no se puede prefigurar o predecir. El estudio de lo que sucede es lo que permite intervenir pedagógicamente en el evento que tiene lugar en el espacio museal (Martinón, 2006).

- El ambiente rodea a los sujetos y los hace participar de él, no sólo observarlo (Hayward, 1992). Eso incluye a las otras personas con quienes se comparte dicho ambiente.

Ahora bien, las investigaciones utilizadas en este artículo fueron registradas en las siguientes fuentes:

- En museos o complejos culturales consolidados que poseen departamentos dedicados a la investigación. Algunas veces estos investigadores publican en revistas especializadas o libros físicos o virtuales. Este es el caso del San Franklin Institute, donde la Dra. Minda Borum es la directora de investigación y, además, una autoridad en educación sobre museos. En Estados Unidos de Norteamérica ${ }^{4}$ es posible ubicar instituciones museales con departamentos dedicados a la investigación. Por ejemplo, el Smithsonian Institute, que cuenta con un equipo de investigación que conforma un departamento. Este complejo cultural ha elaborado una base de datos de estudios de visitantes de museos

\footnotetext{
4 Otros enlaces importantes son: http://www.visitorstudiesarchives.org/index.php, http://www.informalscience.org, http://oerl.sri.com, http://www.eval.org/Resources/bibliography.asp, http://ericae.net/ftlib.htm, http://www.policy-evaluation.org, http://www.astc.org/resource/visitors/index.htm
} 
(http://sirismm.si.edu/siris/siris-museum-studies.htm), así como la lista de universidades que ofrecen programas de estudio y entrenamientos especiales en el campo.

- En revistas de museos organizadas por universidades que ofrecen planes de estudios a nivel de posgrado como el caso de la Universidad de Leicester en Inglaterra que publica la revista Museum and Society, una de las más reconocidas, y la Universidad Complutense de Madrid, que tiene la Revista de Museología. También, está la Academia de Ciencias de California, que publica Curator the Museum Journal. Otras revistas son publicadas por redes y asociaciones de museos como el caso de la Collections Australia Network y la Museum Journal de la Asociación de Museos estadounidenses. Asimismo, es posible encontrar revistas de gremios de profesionales en el campo, como es el caso de la revista de la Asociación Profesional de Museólogos de España, mientras que otras revistas son publicadas por un Museo en particular, como el caso del Museo de Louvre, con su propia revista.

- En casas y editoriales como Roundtable, que desde 1973 promueve y divulga información sobre la educación de museos en la revista Museum Education. Además, Routledge Taylor and Francis Group de Inglaterra, una de las casas de publicaciones más reconocida en el tema de museos, pues ofrece dos revistas: Visitor Studies y Museum Management and Curatorship, y una gran cantidad de libros sobre el tema. Algunas casas editoriales que realizan varias publicaciones en museos son las españolas: Ariely Trea.

- En trabajos finales de graduación de diferentes carreras universitarias y diversos grados académicos. Así como, revistas especializadas de ciencias naturales y sociales que esporádicamente cuentan con publicaciones en temas sobre museos.

- En empresas o consultores dedicadas a realizar estudios de visitantes a museos, especialmente en el ámbito de la evaluación. Un ejemplo es Korn y Associates, Inc. (2003 y 2000), y un consultor es Shettel (2001, 2002, 2004 y 2007).

\section{Los programas de investigación museográfica}

Con base en los estudios registrados quedan establecidos cuatro programas de investigación museográfica que contribuyen a la comprensión del fenómeno pedagógico museal, ellas son: investigaciones centradas en lo museográfico, investigaciones centradas en 
el comportamiento museal, investigaciones centradas en las interacciones público-exhibición y investigaciones evaluadoras. A continuación, una tabla resumen:

Tabla No. 1

Programas y subprogramas de investigaciones museográficas

\begin{tabular}{|c|c|}
\hline Programa & Subprograma \\
\hline \multirow[b]{2}{*}{$\begin{array}{c}\text { Investigaciones centradas en lo } \\
\text { museográfico. }\end{array}$} & Centradas en el objeto expositivo. \\
\hline & Centradas en el recorrido diseñado para la exhibición. \\
\hline \multicolumn{2}{|c|}{ Investigaciones centradas en el comportamiento museal. } \\
\hline \multirow[b]{2}{*}{$\begin{array}{c}\text { Investigaciones centradas en la } \\
\text { interacción dispositivo- } \\
\text { visitantes. }\end{array}$} & Interacción comunicativa mediante la lengua. \\
\hline & Interacción como intercambios secuenciales objeto-sujetos. \\
\hline \multirow{4}{*}{ Evaluación. } & Diagnóstica o Front-End. \\
\hline & Formativa. \\
\hline & Remedial. \\
\hline & Sumativa o de impacto. \\
\hline
\end{tabular}

Fuente: elaboración de la autora.

Los programas de investigación para los estudios de visitantes a museos, sobre aspectos educativos en el contexto de la museografía didáctica expuestos en la Tabla No. 1 y pertinentes al interés de esta investigación, ${ }^{5}$ son detallados a continuación.

\section{Primer programa: investigaciones centradas en lo museográfico}

En el programa de investigaciones centradas en lo museográfico es posible delimitar dos subprogramas, definidos cada uno como corresponde.

El primer subprograma identifica qué características de diseño o propias tienen los objetos más visitados y por más tiempo, cuál es su poder de atracción de la atención de las personas visitantes, qué tipo de interacciones se generan con él que sugieran algún fenómeno educativo y cuáles fenómenos educativos están sucediendo en esos encuentros visitante(s)-objeto.

5 Es necesario aclarar que los programas son complementarios entre sí para comprender la realidad del hecho educativo en el Museo. 
En este sentido, varias investigaciones (Korn y Asociados, 2000; Hein y Alexander, 1998 y Serrell, 1998), con público en general, han reportado el hecho de que los visitantes tienden a utilizar más dispositivos "interactivos" o "Hands on" que los paneles u objetos de lectura y observación. El mayor grado de participación sensorial con los objetos es posiblemente uno de los criterios de esta preferencia.

En esta materia, Berlyne (1972) refiere que para que se mantenga la atención en un objeto, es necesario que los estímulos posean propiedades colativas, ellas son: la novedad ${ }^{6}$, la sorpresa y la incongruencia entre las expectativas y la información que contiene lo que se percibe.

Lo novedoso en este contexto (Berlyne, 1972; Hwahsu y Cols. 2005; Houston-Price y Nakai, 2004) trata de una sucesión de estímulos no familiares al perceptor en el sentido de la variación de la frecuencia del estímulo conocido: es lo que provoca incertidumbre por lo que sucederá luego. Así, la novedad es entendida como un cambio temporal que produce sorpresa y que puede ocurrir en un minuto o a lo largo de la vida del sujeto, en una secuencia de estímulos nuevos o repetidos en el transcurso del tiempo.

Por su parte, Vilnitzky (2005) señala los elementos museográficos que permiten una comunicación efectiva entre un Museo interactivo y el público. La investigadora ofrece un estudio de estadística comparativa referido a exhibiciones interactivas sobre medio ambiente y salud. El estudio es realizado en cinco diferentes países latinoamericanos, entre ellos, el Museo de los Niños de Costa Rica.

Trabaja con niños y niñas de edades entre los 7 y los 9 años, y el público en general. Encuentra que cuando las personas ingresan a una sala de exhibición existen algunos dispositivos que son más "exitosos", pues son más utilizados, o sea, por más cantidad de personas (adultos y la niñez) y por más tiempo respecto de los otros, y los caracteriza como juegos que necesariamente presentan todas las características que se indican a continuación:

- Capturan la atención. Estos dispositivos poseen detalles o formatos que atrapan la atención de los visitantes: ubicación en lugares cerrados, formas extrañas o diferentes a lo usual, lugares con colores que motivan y dan energía para involucrarse con ellos, elementos móviles.

6 Respecto de la novedad, dado que los seres humanos somos una unidad bio-psico-social, resulta de sumo interés que biológicamente, al igual que otros seres vivos, estamos predispuestos a percibirla tanto en el plano visual 
- Promueven una relación física entre el dispositivo y el visitante. Se seleccionan dispositivos con los cuales es posible interactuar físicamente (con el cuerpo).

- Permiten realizar una actividad y obtener un objetivo. Ejemplo: tirar las bolas y lograr un resultado.

- Muestran el resultado de la actividad realizada.

En este sentido, el reconocido investigador estadounidense Bitgood (2000) encuentra, en sus múltiples investigaciones, que si los visitantes no pasan por un dispositivo es porque definitivamente no captó su atención. El autor indica que para entender cómo los visitantes caminan en el espacio, es importante considerar varios aspectos propios de los objetos y su ubicación en el espacio, entre los cuales están los siguientes:

- La atracción de un objeto saliente. Un objeto grande influenciará la circulación, creando una tendencia a que los visitantes se muevan hacia él o se acerquen después de observar el ambiente. Dichos objetos influencian la ruta de manera que minimiza la atención hacia los otros menos salientes.

- Disposición de objetos o exhibiciones. La disposición de los objetos en el espacio determina cómo la gente se desplazará. En cada espacio museal existen "los puntos calientes" y "los puntos fríos" de atención del visitante que se pueden determinar, en gran parte, por los patrones de la circulación. Cuando el flujo es caótico, los visitantes tienden a pasar desapercibido algún elemento.

- Aislamiento. Un objeto aislado de otros tiende a llamar la atención de los visitantes. Entre mayor cantidad de estímulos rodeen a un objeto, menos será notado, especialmente si los estímulos refieren aspectos diferentes.

- Tamaño. La atención se incrementa conforme aumenta el largo y el ancho del objeto. Obviamente con una apropiada escala según el caso.

- Contraste con el set de fondo. El fondo puede hacer "ruido" al punto de que dificulte la detección del dispositivo, de ahí la importancia del contraste.

- Características multi-sensoriales. Agregar sonido, olor o tacto a la interacción con un dispositivo puede aumentar el nivel de atención. Sin embargo, un estímulo no diseñado 
cuidadosamente para complementar con los otros puede competir con ellos y causar lo contrario.

- Iluminación. El nivel total de la iluminación es importante en la determinación de si un dispositivo será notado o no. El contraste entre un objeto y su alrededor producido por un rayo de luz es otra forma de hacer que un elemento sea más detectable.

- Ubicación en la línea de mira. Un objeto que cae fácilmente dentro de la línea de mira de un espectador resulta de más fácil detección.

En esta dirección sobresale el trabajo de Jensen (2006), quien con una metodología observacional y utilizando un marco teórico cognitivo logra determinar cómo los dispositivos de ciencias con diseños artísticos, y muchas posibilidades cognitivo sensoriales de uso, captan más la atención y la sostienen en el tiempo, así como la posibilidad de recordar de lo que trata el dispositivo.

Veamos el estudio de Serrell (1998) titulado: "Paying Attention: Visitors and Museums Exhibitions", donde el interés de la autora es construir un método de investigación para conocer la efectividad educativa del uso de las exhibiciones, y con esto generar un modelo estandarizado de interpretación de datos para establecer parámetros de éxito de las exhibiciones. Es un estudio comparativo entre ciento diez exhibiciones de museos estadounidenses, lo que les tomó ocho años de investigación.

Su fundamento teórico tiene un complemento del enfoque conductista y también de la psicología cognitiva. Los supuestos teóricos de la investigación son:

- La forma en que se utilizan las exhibiciones es apropiado para evaluar su impacto educativo.

- Through use es un concepto clave, que significa que los visitantes están largo tiempo en la exhibición y que la utilizan con una alta proporción de los elementos disponibles.

- Si los visitantes están más tiempo en las exhibiciones las entienden mejor.

- Existe una correlación positiva entre el tiempo de duración del visitante con la exhibición y el aprendizaje.

- Si se observa un comportamiento de aprendizaje puede inferirse que está teniendo lugar ese hecho educativo. 
- Si los visitantes no encuentran que las exhibiciones son atractivas para disfrutarlas o que sean personalmente significativas, cambian su atención.

Esta investigación sigue una lógica cuantitativa que se puede resumir de la siguiente manera:

- Medición del tiempo en sala con relación al tamaño y tiempo en cada elemento museográfico. El tiempo que la gente no pasa en las exhibiciones es excluido. Para esto se utiliza el cronómetro, planos especiales de registro de las observaciones y grabación en vídeo de la actividad en salas.

- Entrevistas a los visitantes.

- Comparan datos entre 62 museos, de los cuales son seleccionadas 110 exhibiciones. Un total de 8.000 visitantes fueron investigados.

- Sobre las conclusiones del método empleado, la autora señala que la medición de 40 visitantes es suficiente muestra para plantear tendencias generales. En este sentido, el método revela patrones generales, pero no especificidades de subgrupos.

- La muestra de 110 exhibiciones es suficiente para sugerir conclusiones, sin embargo, son necesarios estudios estadísticos adicionales que capten la realidad de museos con poco personal y presupuesto mínimo.

De los resultados obtenidos de la investigación propiamente, se afirma que:

- Los visitantes no pasan mucho tiempo en las exhibiciones, duran al menos 20 minutos o menos en promedio para cada exhibición.

- Es común que las exhibiciones se exploren parcialmente. Pocos visitantes (solo el 26\%) ponen atención a más de la mitad de los elementos de una sala. Este hecho supone un serio problema para el cumplimiento de los objetivos educativos, especialmente en las exhibiciones largas, complejas y temáticas.

- Mientras más tiempo duraron los visitantes en una sala, más tiempo le dedicaron a un dispositivo de exhibición.

- 300 pies cuadrados por minuto es la velocidad promedio del visitante en su recorrido al Museo. 
- No se deben realizar exhibiciones de un tamaño menor a 1.000 pies cuadrados (92.95 $\mathrm{mts}^{2}$ ). En cada sala de ese tamaño debe haber únicamente entre 40 y 50 personas para garantizar un mejor aprovechamiento de las exhibiciones.

Pese a que la investigación de Serrell (1998) denota un interés en lo educativo, falta un análisis final en este sentido. Sin embargo, un aporte importante de la investigación es el hecho de considerar que para que se dé el hecho educativo en el Museo es necesario el tiempo.

Esta variable de duración en la visita es necesario rescatarla y reelaborar este concepto de proceso de aprendizaje asociado con la acción del individuo sobre el dispositivo, y contemplar las demás interacciones en el contexto de la visita.

Además, es importante considerar el hecho de que una tendencia en el diseño de exhibiciones en la actualidad es lograr objetos museográficos que obliguen al visitante a interactuar necesariamente en grupo, superando la experiencia individual.

Este subprograma de investigación, en una sistematización de sus resultados, permitiría sistematizar las condiciones de diseño y exposición de los objetos museográficos que determinan su poder de captar la atención del público, como para iniciar un proceso de interacción más complejo centrado en las posibilidades de interacción que dicho elemento provee. Estarían determinándose aspectos de diseño, pero en términos de tecnología educativa, en tanto que lo que se busca es orientar la atención para propiciar ciertos tipos de participación deseada que trascienda de "hands on" hasta "minds on" y "hearts on" (Wagnensberg, 2004).

Podemos sintetizar este subprograma siguiendo a Brown (1995), quien con base en sus resultados de investigaciones con visitantes a museos concluye que existe algo en la naturaleza de los objetos museográficos que hace que unos elementos, por su particular diseño, tengan la posibilidad de atraer la atención de las familias (su población de estudio), mientras que otros no.

El segundo subprograma de investigaciones centradas en lo museográfico consiste en determinar la influencia de una específica disposición física de los dispositivos en un espacio, en la forma en la cual los visitantes recorren una sala.

Interesa determinar cómo los agentes externos al visitante influyen en el proceso educativo. Los recorridos, la ubicación de mobiliario, las paradas y las rutinas de desplazamiento son estudiadas desde la perspectiva etnográfica y etológica. 
El método de investigación de este tipo de estudios suele ser basado en lógicas cuantitativas de investigación. Sin embargo, algunos estudios complementan las metodologías con la etnografía, pero predomina la lógica cuantitativa.

Es importante señalar que el enfoque conductista está presente en el estímulo-respuesta asociado con el comportamiento de las personas en función del manejo de variables que el Museo haga, pese a que los autores algunas veces indican que se trata de un enfoque cognitivo, de hecho, Zahava (March, 1999) indica que los estudios conductistas son los más comunes en Estados Unidos de América. Otros estudios en esta línea son los de Gilbert y Stocklmayer (2001), Winerman y Peponis (2010) y Klein (1993).

En este contexto, Bitgood (2010), en sus investigaciones sobre circulación de visitantes en salas, concluye que la forma en que los visitantes circulan en una sala determina qué ven, dónde focalizarán su atención y, en última instancia, lo que aprenden y cuáles experiencias tendrán.

En otra publicación, Bitgood y cols. (1991) realizan una investigación de la circulación de visitantes en cinco exhibiciones sobre ciencias naturales en el Anniston Museum of Natural History. El interés de su estudio radicó en conocer, entre otros aspectos, cuánta influencia ejerce en el comportamiento de los visitantes la disposición de objetos en una sala de exhibición. Utilizaron una metodología observacional in situ sin intrusión. Concluyeron que los patrones de circulación lineales, dispuestos así desde el diseño de una sala, son los más claros para el visitante, los siguen sin perderse (en otros tipos de disposiciones del espacio se perdían y omitían objetos) y aprovechan más tiempo en zcada uno de los objetos. Otra conclusión fue que los objetos atractivos influencian la circulación y también la pueden guiar de un punto a otro en una secuencia lineal de circulación.

La idea de estos estudios es mostrar que los diferentes recorridos suponen estrategias diferentes de apropiación del conocimiento. El foco central es mostrar que el recorrido puede ser subliminalmente orientado por el Museo, para mejorar el proceso educativo.

En síntesis, una modificación en el espacio y, por lo tanto, en los objetos que lo integran, puede significar un cambio en el uso de los elementos museográficos y en el tiempo dedicado a cada uno. En todo caso, la actividad espacial es efímera en su naturaleza, por lo tanto, se perpetúa en el tiempo como un constructo virtual siempre en proceso de definición.

Por último, resulta interesante mencionar que este tipo de estudios no ha sido registrado en Latinoamérica y son escasos en relación con los demás tipos de investigación. 


\section{Segundo programa: investigaciones sobre el comportamiento museal}

En el programa de investigaciones centradas en el comportamiento humano en un medio museográfico, el interés está en identificar el comportamiento que evidencie procesos de enseñanza-aprendizaje informal, según diferentes tipos de visitantes.

Algunos ejemplos de este tipo de investigaciones las encontramos en Anderson y Lucas (1997), Alcorta y Ayala (2006), Leinhardt y Crowley (1998) y Leinhardt y cols. (2002), quienes estudian las conversaciones que las personas sostienen en el uso de los dispositivos para comprender cómo sucede la construcción de sentido entre los visitantes. También, Barreiro (2009) y Kuflik y cols. (2009), quienes delimitan predictores de patrones de comportamiento en museos.

Mientras tanto, Packed y Ballantyne (2005) investigaron la diferencia que se presenta cuando una persona visita sola una exhibición y cuando la visita acompañada. Ellos encuentran comportamientos muy diferentes en el medio museal, y afirman que es posible identificar comportamientos de aprendizaje diferentes entre los dos tipos de visita, por ejemplo, reportan que las personas solas aparentan leer ${ }^{7}$ más que las personas acompañadas, y que las acompañadas pasan más tiempo con los objetos museales que las primeras.

Otros estudios de este programa son los de Packed y Ballantyne (2005), Bonderup (2011), Crowley y Galco (2001), Crowley y cols. (2001a. 2001b), Crowley y Callanan (1998), Lewin-Benham (1997), McClafferty (2000), así como el de Rix y McSorley (July, 1999), quienes estudian las conversaciones de las personas, según características socio demográficas, ante los objetos.

Una de las investigaciones más representativas es la de Tolsa y cols. (2002) realizado en México en el Museo Franz Mayer, donde la preocupación de los investigadores es dar a conocer los aprendizajes que los sujetos construyen en torno a los objetos. Este estudio, que lo consideraron pionero en el ámbito de los museos en su momento, compara el comportamiento de los visitantes en dos salas del mismo Museo y lo plantean desde un enfoque constructivista. Un eje metodológico de su investigación es la técnica llamada "Talking Aloud", que consiste en registrar los comentarios que los visitantes hacen en torno a las exhibiciones para su análisis.

7 Eso significa que no es posible saber si realmente leen, solo que aparentan hacerlo. 
Ahora bien, el estudio plantea un análisis de los datos basándose en Vigotsky, que sigue tres aspectos centrales respecto al aprendizaje, estos son: las habilidades intelectuales 0 cognitivas, la carga afectiva y la actividad imaginativa del visitante a lo largo del recorrido.

Los resultados muestran que ninguno de los grupos visitantes (estudiantes de lo que ellos llaman "preparatoria", amas de casa, profesionales y especialistas) remitió la presencia de procesos mentales, tales como: asociación, clasificación o síntesis en su relación con las exhibiciones. El $85 \%$ de las actividades cognitivas registradas pertenecen a funciones primarias, el $15 \%$ restante a actividades de construcción mental, esto último en el grupo de especialistas.

De esta manera, para acercarse a las exhibiciones las amas de casa utilizan un auto referente, mayor carga afectiva, necesidad de un guión más estructurado para contextuar los objetos, interpretaciones erradas de lo que se exhibe; mientras que los profesionales perciben los objetos en un contexto de mayor abstracción que el grupo anterior y logran contextuar la procedencia y la temporalidad.

Por su parte, los especialistas exponen una visión mucho más integral (pasado, presente y futuro), consideran al objeto como vehículo de la idea y expresan la ausencia de temáticas. De esta manera, es notorio que el nivel educativo es un aspecto central para la interpretación de las exhibiciones, este aspecto es tomado en cuenta en la selección de grupos familiares.

En este programa existe, además, el estudio de Tolsa y cols. (2002), quienes llegan a conclusiones sobre la imaginación en la interpretación de exhibiciones: afirman que la aproximación del visitante a las exhibiciones, por medio de sus preconcepciones, son los principales medios para el aprendizaje en el Museo.

Si bien esta investigación tiene un parecido con el programa anteriormente expuesto, la diferencia está en el enfoque del estudio hacia el aprendizaje como construcción mental y no hacia el proceso de comunicación objeto-sujeto.

En este sentido, Gutterman y otros (2000) encuentran que en el Museo son consolidadas ideas previas y erróneas que las personas traían antes de la visita. Además, muestran que el proceso de aprendizaje está centrado en: la curiosidad generada por las ambientaciones y la confianza en sí mismo, pues el visitante despliega cualidades y asume responsabilidad sobre sus acciones respecto al objeto; el desafío de interactuar con el medio, el autocontrol y la autodeterminación en el trabajo-juego en grupo, el aprender jugando y la dinámica del Museo 
favorecen la interacción comunicativa en el ámbito social. Del mismo modo, es importante conocer la dinámica de visita de las familias.

Otro de los estudios relevantes en este programa es el que exponen Crowley y otros (May, 2001b) titulado: "Parents Explain More Often To Boys Than To Girls During Shared Scientific Thinking". Estos autores partieron de varias investigaciones psicológicas que mostraban cómo los maestros en el aula fomentaban más en los niños que en las niñas el plantear preguntas, hacer comentarios y sugerir explicaciones de lo que se estudia.

Con base en lo anterior, los autores proponen responder la pregunta: ¿existirá una diferencia de género similar entre los padres y los hijas/hijos, que se pueda hacer notar en las conversaciones que tienen lugar en el aprendizaje informal de la ciencia en el Museo?

El método utilizado consiste en lo siguiente:

- La muestra de la investigación incluye 298 interacciones de diferentes familias.

- Para la recolección de datos se utilizó una vídeo cámara y micrófonos ubicados en 18 exhibiciones interactivas de ciencia en el Museo de los Niños de California. Fueron seleccionados dispositivos que no necesitaran la participación de un adulto para ser manipulado por un niño. Los datos fueron tomados durante 26 días a lo largo de un periodo de 30 meses, incluyendo todos los días de la semana en el verano y en el periodo escolar.

- Las conversaciones fueron codificadas como explicaciones sobre conexiones causales que mostraran las exhibiciones, relaciones entre lo observado y principios generales, analogías con relación al fenómeno. Otra de las formas de codificar los diálogos fueron las indicaciones que los padres/madres dieron sobre las formas de uso de las exhibiciones, sobre las evidencias que podían observarse en los dispositivos.

- Las acciones fueron codificadas partiendo de la acción del padre o madre y el niño sobre el dispositivo (no se graba quién toma la iniciativa de interactuar con el objeto). No fueron consideradas acciones parciales sobre el dispositivo, sino las acciones que exitosamente completan el uso dispuesto por la estructura y los objetivos del dispositivo.

Los resultados arrojaron que los niños y niñas, en general, tienen un papel activo en el uso de las exhibiciones interactivas; en este punto no hay diferencia significativa entre la iniciativa por género. Tampoco existe una diferencia significativa de género en la manipulación de las exhibiciones ni en el tiempo de duración interactuando con ellas. 
Otro aspecto en común fue el hecho de que a ningún niño le gustaba escuchar explicaciones en torno a los dispositivos (principios generales y analogías) de parte de sus padres/madres o del personal del Museo.

Con respecto a las explicaciones sobre cómo utilizar las exhibiciones, los padres/madres mostraron igualdad en el trato con los niños de las diferentes edades. La diferencia de género encontrada fue que los padres/madres suelen dar explicaciones sobre temas de ciencia más frecuentemente a los niños que a las niñas. Lo más notorio es que son los padres/madres quienes introducen a los niños de 1 a 3 años en el tema de la ciencia, antes que la educación formal lo haga.

En conclusión, los padres/madres que involucran a los niños y a las niñas en actividades informales de ciencia, les proveen la oportunidad de ir aprendiendo sobre los hechos científicos, de desarrollar el interés en aprender sobre la ciencia, y los sensibiliza hacia los hábitos de la lectura científica.

Sin embargo, este potencial de los padres/madres en promover estos valores e intereses científicos, entre las niñas, hasta el momento, no fue notado un desarrollo. Otras investigaciones que muestran resultados similares son las que exponen Diamond (1986) y Dierking y Falk (1994), donde se establece que existen diferencias de roles por género basadas en las interacciones de los grupos familiares en el Museo.

De hecho, Dierking y Falk señalan que los padres/madres hacen diferencia según el género de sus hijas/hijos, quienes influencian el aprendizaje y que este hecho debe estudiarse más a fondo.

Además, no incluir los datos obtenidos de los usos incompletos de los dispositivos puede sesgar los resultados, pues quién toma la iniciativa de "abortar" la actividad y cómo lo hace puede resultar de interés para el problema planteado.

En este sentido, la conclusión del interés de los padres/madres en enseñar ciencia a los niños y no a las niñas, debe comprenderse en el contexto de las interacciones exitosas únicamente. Además, es necesario estudiar las relaciones padres/madres-niños-exhibiciones, de manera que pueda comprenderse cómo actúa el hecho educativo, teniendo claro que no hay error y acierto, sino que todos los datos serían información necesaria para comprender la realidad del Museo desde una perspectiva educativa más holística.

Mientras tanto, Shine y Acosta (2000) plantean otra investigación que puede ubicarse en este programa de estudios; el título del trabajo es: "Parent-Child Social Play in a Children's 
Museum". Este reporte de investigación muestra dos estudios sobre familias visitantes al Museo de los Niños del centro de Texas, y proponen revelar los aportes de los padres/madres al juego de roles para el aprendizaje entre los grupos familiares, detallaremos, a continuación, uno de ellos para ilustrar este programa: las interacciones padres/madres-hijas/hijos en un Museo de exhibiciones contextuales durante un juego de roles.

El estudio fue realizado en un contexto natural de observación en el Museo de los Niños del centro de Texas. Los participantes fueron 30 parejas de padre-hijo: doce madre-hija, cinco madre-hijo, ocho padre-hija, cinco padre-hijo, todos de aparente etnia caucásica; fueron seleccionados niños de 4 a 6 años, pues en unas observaciones piloto pudo notarse que ese grupo de edad dialogaba más durante el juego.

Para el análisis de datos fue utilizado la Grounded Theory, donde las categorías de análisis son inductivas. Este proceso fue efectuado en cuatro fases: una inicial de codificación abierta para determinar las categorías de análisis; la segunda fase fue de selección de códigos para determinar el núcleo categórico del análisis; la tercera fase fue de organización de los datos sobre un argumento central y, por último, la ubicación de los datos en una matriz condicional que reflejen las estrategias de los participantes y las consecuencias de las estrategias en el juego de interacciones.

Los resultados indican que los padres/madres y los hijas/hijos interactúan en el juego de roles de manera breve, esporádica y con interacciones no contingentes. Además, pudo notarse que más que lograr que las familias estén inmersas en un escenario imaginario, los padres/madres intentan guiar el juego para enseñar a los niños tanto lógico-matemática como conceptos sociales y para dirigirlos en comportamientos pro sociales. En este sentido, los padres/madres no logran integrarse al juego de roles, puesto que les interesa más enseñar a sus hijas/hijos lo indicado anteriormente.

Los investigadores remiten que los padres/madres son quienes organizan la experiencia del juego entre estos niños, les informan sobre los procedimientos, dirigen su atención hacia el equipo y prueban su conocimiento de conceptos. La guía de los padres/madres sirve de puente entre el conocimiento de los niños y las metas educativas de la exhibición del Museo de los Niños. En consecuencia, sugieren que los museos deben facilitar la entrada de los padres/madres en la estructura de los juegos que ofrecen las exhibiciones para lograr un mayor aprendizaje de los niños. 
Otro reporte de investigación de este programa lo expone Arámbula (1995). Su estudio trata sobre las diferencias en el comportamiento de niñas y niños, sin compañía de adultos, ante las exhibiciones interactivas de un Museo en Honolulu, Hawai. Encuentra que existen temas y tipos de dispositivos que son interés diferencial para la niñez, según sexo. También, que las niñas presentan más comportamientos de aprendizaje cooperativo y los niños más comportamientos de aprendizajes competitivos en la resolución de problemas. Otra de sus conclusiones es que los niños duraron más tiempo que las niñas en el uso de los dispositivos.

Por último, es necesario destacar que el Smithsonian Institution (2002) indica que una de las principales tendencias en investigación, en la última década, es precisamente en este paradigma enfocado en el aprendizaje de los visitantes con las exhibiciones. Esto tiene relación con la concepción del visitante como un educando activo, con entender que los procesos de aprendizaje del visitante no necesariamente están acordes con la propuesta museográfica, pues existen muchos factores que intervienen en este proceso educativo.

Dierking (2002) afirma que, en la actualidad, se está en una etapa de transición en la que la unidad de análisis en los diseños de investigación de museos pasa del individuo al grupo (familias, amigos, grupos escolares, etc.). Esta preferencia se nota en todos los programas de investigación en museos señaladas en este apartado. Este cambio radica en el hecho de haber comprendido que las unidades de aprendizaje en un Museo no son individuos aislados, sino los grupos pequeños con los cuales estos hacen su visita (Borum, 2002) especialmente en el contexto del aprendizaje socialmente situado.

En conclusión, Martinón (2006) afirma que el Museo no es simplemente una institución dada y acabada, sino un espacio expuesto a interpretaciones o co-construcciones virtuales del objeto; procesos sociales de disolución y de restauración, de fractura y de re-enlace de sentido durante el recorrido de los visitantes.

Es de suponer, entonces, que si las personas visitantes ingresan a la exhibición como parte de un grupo escolar en una gira educativa, como parte de un grupo familiar en su tiempo libre, como parte de un grupo de amigos de paseo de fin de semana o vacacional, de manera solitaria o acompañando a una persona interesada en conocer una exhibición, lo emergente se presentará de manera diferente y diversas interacciones se producirán con lo museográfico.

Leinhardt y cols. (2002) encuentran que en las conversaciones entre las personas adultas que cuidan de niños y niñas son establecidas ayudas y puentes de comunicación que permiten a las personas menores comprender mejor una exhibición y promover el interés en un tema. 
Debido a lo anterior, señalan que los diseñadores de exhibiciones deben tener una explícita intención en asistir a las personas adultas en el proceso de enseñanza-aprendizaje de los niños y las niñas, mediante sistemas de símbolos, herramientas, recreación de escenarios, textos, actividades estructuradas, colores y organización de las formas de circular en la exhibición. A estas ayudas las llamamos: orientaciones pedagógicas, las cuales deben ser pensadas desde el diseño y desde la educación de museos.

\section{Tercer programa: investigaciones sobre interacciones dispositivo-visitantes}

Este programa de investigación centrado en las interacciones dispositivo-visitante cuenta con dos subprogramas. A continuación se detalla cada uno.

El primer subprograma es el de la educación en los museos entendida como un proceso de comunicación entre visitante(s)-exhibición, mediante el lenguaje. De este modo, se parte de que el papel educativo del Museo es comunicar en los códigos de su público, contenidos e información en general y de esa forma provocar interacciones con orientación pedagógica.

Algunas investigaciones en esta línea son las que plantean autores como De las Nieves y otras (2002), Bialogorsky y Cousillas (2002), Knutson y Crowley (2010), Altamirano y otros (1998), Kmetz (May, 1993), Abu y Leinhardt (2000), Sortiño (2000), Korn y Associates (March/April, 1994), Crowley y otros (1998), Allard y Lacouche (octubre, 1994), Mantecon (1996), por mencionar algunos. Todos ellos se interesan en el hecho educativo como un proceso comunicacional.

En este tipo de investigación están presentes los estudios de semiótica, como por ejemplo, el de Bialogorski y Cousillas (2002). Estas autoras trabajan en un análisis semiótico mediante construcciones del discurso, utilizan técnicas tales como entrevistas, encuestas y comentarios que las personas plantean sobre las exhibiciones en el Libro de Visitantes del Museo ${ }^{8}$. Su interés está en lo incluido en los discursos (la tradición del gaucho) y lo excluido (lo indígena).

En términos generales, puede decirse que los ejes de análisis de este grupo de investigaciones están ocupados en demostrar que el hecho educativo no se da en el sentido que las exhibiciones lo plantean, sino en que los visitantes cuentan con su propio sistema de

\footnotetext{
8 Algunos museos suelen ubicar en un lugar de la exhibición, libros donde las personas pueden anotar sus comentarios y observaciones sobre su visita.
} 
interpretación de las exhibiciones y esto está asociado con las preconcepciones de las personas.

En síntesis, existe un divorcio entre lo que enseña el Museo y la forma en que se hace (didáctica museística), y entre lo que la gente comprende y cómo lo hace (didáctica informal). Estos resultados son vitales para comprender la dinámica de las personas visitantes en sus interacciones con las exhibiciones.

El segundo subprograma de investigación refiere al encuentro visitante-objeto como un proceso interactivo que involucra una secuencia de participación del sujeto con el objeto y eventualmente con otras personas que le acompañan.

En este subprograma está la investigación de Blud (1990) sobre el rol de la interacción social como promotora del aprendizaje en los grupos familiares compuestos por niños y adultos. Los resultados de esta investigación comprueban que, en el caso de las exhibiciones interactivas, estas facilitan un ambiente social para la discusión constructiva de conocimiento entre visitantes. Otros estudios en esta línea son los de Wasserman (2011), Everett y Barret (2009), Rodríguez (2008), Vom Lehn y cols. (2001), Mortensen (2011) Piscitelli y Weier (2002) y Borum (2002).

En el caso de Borum (2002), mediante diferentes investigaciones de interacciones familiares con dispositivos, la investigadora indica que las características de los dispositivos son las que permiten las actividades familiares:

- Multilados: la familia puede ubicarse junta alrededor del objeto.

- Multiuso: la participación con el dispositivo permite a varias personas a la vez.

- Accesible: ergonómicamente adaptado para niños, niñas y adultos.

- Multioutcome: lo que se observa y se hace es suficientemente complejo como para promover la discusión grupal.

- Multimodal: considera diferentes estilos de aprendizaje y niveles de conocimiento.

- Legible: el texto está estructurado en segmentos fácilmente comprensibles.

- Relevante: provee conexiones cognitivas con los conocimientos y experiencias de los visitantes.

Al respecto, muchas investigaciones reportan que los grupos familiares cuentan con una agenda específica al visitar los museos y que dicho interés gira en torno a mantener 
interacciones sociales al interno de su grupo (Borum, 2002; Hein y Alexander, 1998; Ellenbogen, 2002; Rodríguez, 2008; Borum y otros, 1998).

\section{Cuarto programa: evaluación museográfica}

En este programa de investigación interesa valorar a las exhibiciones en términos de sus objetivos educativos. La tendencia de la evaluación es positivista, con estudios cuantitativos cuyo eje es la encuesta y la observación estructurada, aunque, también, existen algunos estudios cualitativos. Algunas investigaciones en este programa las presenta Hodge y cols. (1994), Borum (March, 2003), Korenic (2002), Pérez (1998), Serrell (2006) y Korn y Jones (1998).

Según Pérez (2000) la evaluación museográfica en el campo educativo inicia en la década de los años setenta y sus principales exponentes son Screven y Shettel. De la revisión bibliográfica efectuada se nota que Screven (1993) es uno de los autores estadounidenses que ha elaborado más este enfoque en el nivel teórico, y en Europa es Hein (1994).

Ahora bien, los estudios museográficos en este programa se diferencian de los otros en su intencionalidad evaluativa explícita. Si bien estos estudios pueden efectuarse desde los programas anteriores y respondiendo a sus intereses centrales, su fin último es valorar una exhibición museográfica.

La evaluación en su clásica delimitación según sea: diagnóstica, previa o Front-End Evaluation; formativa o de proceso; sumativa y la evaluación remedial (Remedial Evaluation). Esta última se utiliza para medir los logros de las mejoras planteadas como resultado de las evaluaciones diagnóstica, de proceso y sumativa.

Veamos una traducción libre de una tabla de Bitgood (Fall, 1994) realizada por la autora, que sistematiza de manera clara la aplicación de las tradicionales fases evaluadoras al campo de la museografía. 
Tabla No. 2

Tipos de evaluación museográfica según características centrales

\begin{tabular}{|c|c|l|l|l|c|}
\hline $\begin{array}{c}\text { Tipo de } \\
\text { evaluación }\end{array}$ & ¿Cuándo? & \multicolumn{1}{|c|}{ ¿Por qué? } & ¿Cómo? & ¿Qué? & ¿A quiénes? \\
\hline $\begin{array}{c}\text { Diagnóstica o } \\
\text { Front-End }\end{array}$ & $\begin{array}{l}\text { Fase de } \\
\text { planea- } \\
\text { miento }\end{array}$ & $\begin{array}{l}\text { Obtener } \\
\text { Información del } \\
\text { conocimiento del } \\
\text { visitante, ideas } \\
\text { erróneas e } \\
\text { intereses. }\end{array}$ & $\begin{array}{l}\text { Administración } \\
\text { de entrevistas a } \\
\text { potenciales } \\
\text { visitantes. }\end{array}$ & $\begin{array}{l}\text { Planes, ideas } \\
\text { de exhibición y } \\
\text { conceptos } \\
\text { centrales } \\
\text { (cédulas). }\end{array}$ & $\begin{array}{c}\text { Muestra de } \\
\text { tamaño } \\
\text { moderado. }\end{array}$ \\
\hline Formativa & $\begin{array}{c}\text { Fase de } \\
\text { diseño }\end{array}$ & $\begin{array}{l}\text { Mejorar la } \\
\text { propuesta } \\
\text { museográfica } \\
\text { antes de su } \\
\text { producción. }\end{array}$ & $\begin{array}{l}\text { Presenta una } \\
\text { simulación de la } \\
\text { exhibición. }\end{array}$ & $\begin{array}{l}\text { Maquetas y } \\
\text { otros modelos } \\
\text { de dispositivos } \\
\text { individuales. }\end{array}$ & $\begin{array}{l}\text { Muestra } \\
\text { pequeña. }\end{array}$ \\
\hline Remedial & $\begin{array}{l}\text { Post } \\
\text { instalación }\end{array}$ & $\begin{array}{l}\text { Mejorar la } \\
\text { exhibición una vez } \\
\text { expuesta al } \\
\text { público. }\end{array}$ & $\begin{array}{l}\text { Validar la } \\
\text { exhibición } \\
\text { expuesta. }\end{array}$ & $\begin{array}{l}\text { Objetos } \\
\text { aislados y en } \\
\text { módulos o } \\
\text { grupos } \\
\text { temáticos. }\end{array}$ & Muestra \\
pequeña.
\end{tabular}

Fuente: Bitgood. Fall, 2004. Traducción libre.

Algunos ejemplos de los tipos estudios de evaluación señaladas en la tabla anterior y para el ámbito de la museografía nos lo ofrece el Media Evaluation and Visitor Research de la North Carolina State University (estadounidense) en su web http://www.nps.gov/hfc/products/evaluate.htm

En cuanto a la evaluación previa o Front-End Evaluation encontramos investigaciones tales como la de Shettel (February, 2001) y la de Korn y Associates (April, 2003). Mediante estos estudios interesa conocer al público meta en lo que respecta a sus conocimientos e intereses del tema de la exhibición, o bien, si tiene ideas equivocadas o diferentes a las de los museógrafos. En este caso, se realiza antes de diseñar la exhibición y, por lo general, se utilizan entrevistas o grupos focales.

Respecto de la evaluación de proceso o formativa es realizada una vez que se tiene un diseño de exhibición, el cuál debe ser validado por medio de una simulación de los elementos (maquetas, recreaciones tridimensionales, y similares) que conforman toda la exhibición, inclusive los mismos textos que acompañarían a los objetos, con un grupo focal suelen revisarse aspectos específicos que permitan valorar el diseño antes de la producción del 
mismo. Algunos ejemplos de este tipo de investigación los encontramos en Amaze Design y otros (February, 2007a y February 2007b) y Wells (2006).

La evaluación remedial es la efectuada una vez que la exposición ha sido montada. Este tipo de evaluación puede hacerse con dos fines diferentes: el primero consiste en determinar si el montaje cumple con los objetivos propuestos. Dos ejemplos de esta modalidad los ofrecen Bitgood (1996) y Shettel (March, 2002).

El segundo fin de la evaluación remedial trata de realizar investigaciones para determinar otro tipo de aspectos más generales y que aporten la evaluación de los diferentes tipos de diseño museográficos y su función educativa.

En esta línea tenemos el estudio de Zwinkels y cols. (2009), quienes se interesan en evaluar el poder de atracción del diseño de las exhibiciones del zoológico y jardín botánico Rotterdam en Holanda, según tiempo de duración en los dispositivos. Ellos analizan seis exhibiciones de acuarios utilizando un método observacional. Miden tiempos de duración en cada módulo según género, edad y hora de la visita en tiempo vacacional. Encuentran que los visitantes de la mañana pasan más tiempo en los dispositivos que los de la tarde, y que los visitantes que hacen un recorrido general al zoológico y al acuario pasan menos tiempo en las exhibiciones del final del recorrido.

Otra investigación en esta línea de evaluación la exponen Borum y otros (1998), quienes evalúan el aprendizaje familiar en salas de cuatro museos interactivos estadounidenses. Interesados en determinar cómo pueden promoverse comportamientos cuyo resultado sea el aprendizaje, con base en siete características predefinidas que hacen que los diseños de las exhibiciones sean accesibles para las familias (estos criterios se retoman en la unidad de análisis teórica de este documento, como aspectos a considerar para la descripción de los dispositivos donde será realizada la investigación). En este proyecto de investigación evaluativo fueron grabadas las conversaciones y los movimientos de los grupos familiares, para registrar los datos y diferenciar los cambios según la composición del grupo.

En relación con evaluaciones sumativas o de impacto, el Media Evaluation and Visitor Research reporta entre otros dos estudios de Shettel (September, 2004 y August, 2007). Shettel es uno de los principales evaluadores de exhibiciones en Estados Unidos de Norteamérica.

Por su parte, Pérez (Julio, 1995) reporta una evaluación sumativa titulada: "El impacto de las exposiciones en el Museo Nacional de Ciencias Naturales: 5 años de investigación sobre público". A Pérez le interesa evaluar quiénes visitan el Museo, qué hacen los visitantes en el 
Museo una vez que ingresan, cómo usan el tiempo, qué opinan de las exhibiciones y cuál es la comprensión de los visitantes sobre la exposición.

Para esta investigación, se utilizó el S.I.O.R. (Sistema Informático de Observación de Recorridos) que está en fase de perfeccionamiento; este sistema de avanzada tecnología permite la detección de movimientos espaciales en un campo delimitado, para facilitar su registro y cálculos estadísticos. Además, pasaron cuestionarios para medir aspectos varios. Los resultados más importantes de este estudio muestran lo siguiente:

- El $45 \%$ de los visitantes son universitarios y el $55 \%$ restante son estudiantes de primaria y secundaria.

- Del tiempo total que pasan en el Museo los visitantes, sólo 30 minutos está dedicado totalmente a las exhibiciones. El tiempo máximo ante un panel fue de 12 segundos y el promedio de 3 segundos.

- En relación con la opinión de las exhibiciones, por lo general, puntuaron en 7.5 de 10.

- En cuanto a la comprensión de los visitantes sobre la exposición, el $75 \%$ de los encuestados decía haber manipulado alguno de los módulos y recordaba su contenido. En general, se encontró que recordaban mejor los módulos mecánicos y las pantallas interactivas que el resto de los módulos de botón o pasivos.

Actualmente, evaluar es una condición de la calidad educativa de los museos y está dada por estadísticas que muestren el nivel educativo o cualquier otro aspecto medible. El eje de estas investigaciones es el interés en desmitificar conceptos o ideas erróneas previas que maneja el Museo sobre los visitantes, y definir criterios para el diseño de "excelentes" exhibiciones.

Este tipo de investigación no se relaciona directamente con el interés de investigación que se expone, aunque al describir la función educativa y los usos que las familias hacen de los objetos museológicos, de alguna manera se evalúa.

En este último programa de investigaciones es posible notar que en la actualidad hay dos tendencias transversales a los fines expuestos y que refieren a la unidad de análisis, ellas son: la que considera al individuo como centro del estudio y la que considera variables intrapsicológicas y ergonómicas (Serrell, 2006). 
En esta tendencia interesa la medición de contenidos asimilados tras visitar el Museo, con base en los estilos individuales de aprendizaje, y la segunda, que considera al grupo, con el cual el visitante hace su recorrido como unidad de análisis y asocia variables intersubjetivas, interactivas y ergonómicas (Borum, 2002). Aquí interesa identificar situaciones de aprendizaje interactivas entre el grupo de sujetos que visitan juntos, y los dispositivos, para ubicar las características de aquellos objetos y su disposición en el espacio, y para conocer cómo suceden los procesos educativos en museos.

\section{Conclusiones y recomendaciones}

El recorrido a un Museo supone la exploración visual del entorno y la selección de aquellas actividades que resulten de interés para los y las visitantes. En este sentido, la percepción de los objetos (como unidades concretas de las exhibiciones) juega un papel central en la selección de la atención para observar o utilizar, cómo hacerlo y hasta cuándo. La mirada al entorno sucede entonces como un procesamiento de símbolos o información (Bayo, 1987) por parte de los sujetos, en una escena culturalmente estructurada como es una sala museográfica.

Por lo tanto, transcurre de manera secuencial y en el tiempo. La percepción es una decisión interesada del sujeto en la que intervienen el pasado y el presente inmediato, así como otros procesos mentales superiores y donde el marco de referencia cultural y los otros que lo acompañan aportan estructuras y formas de interpretación y participación con dicho medio. De esta manera, inicia el hecho educativo museal con las personas visitantes en este evento emergente. Todos los programas de investigación contribuyen a la comprensión de diferentes aspectos de este evento.

Sin embargo, no es suficiente conocer este evento emergente; existe la necesidad de sistematizar una pedagogía museológica concretada en una didáctica museográfica eficiente para propiciar interacciones orientadas por objetivos predefinidos. Esto en un momento donde los resultados de investigación muestran qué orientaciones pedagógicas suceden entre las personas visitantes y las exposiciones.

Es imprescindible que estos montajes se elaboren de manera interdisciplinar; integrando, además del curador, a diseñadores gráficos, a arquitectos, a artistas, y a educadores de museos que comprendan las posibles orientaciones pedagógicas que desde un tipo de diseño 
se puedan gestar. Los resultados de investigación en el campo son indispensables para diseñar exhibiciones considerando a la museografía como una modalidad de tecnología educativa y, por lo tanto, como una estrategia didáctica.

Por lo anterior, coincidimos con Poll y Asensio (1997, p. 17-18) en que:

...precisamos de una teoría (museológica y museográfica) cada vez más potente que permita barajar con eficiencia un conjunto de criterios de montaje que permitan orientar, prever y optimizar la efectividad comunicativa de los diferentes elementos que componen el diseño de exposiciones: el continente y el espacio expositivo; los propios objetos, obras y fenómenos que componen la razón de ser del mensaje expositivo, su selección y criterios de presentación, los distintos tipos de elementos comunicativos que permitan al público acceder al mensaje...

Sin embargo, esta teoría debe estar sustentada en las técnicas de diseño, y también en criterios pedagógicos fundamentados en los resultados de investigación de lo que sucede en esos espacios, los cuales permitirían una contextualización acertada. Esta es la tarea que tenemos pendiente en el ámbito museológico.

\section{Referencias}

Abu, Mary y Leinhardt, Gaea. (2000). Two Docents in three Museums. Learning Research and Development Center. University of Pittsburgh. Disponible en: http://mlc.Irdc.pitt.edu/mlc

Alcorta, Alfredo y Ayala, Estela. (2006). Saber escolar y didáctica museográfica; algunas reflexiones. Revista de Teoría y Didáctica de las Ciencias Sociales, (11), 193-232.

Alfageme, Begoña y Marín, Teresa. (2006). Uso formativo de Museos Universitarios. Revista de Teoría y Didáctica de las Ciencias Sociales, (11), 263-286.

Altamirano, Carla; Cardinal, María; Di Fiore, María; López, José; Raffellini, Patricia; Ricci, Conrado y Runcio, María. (1998, Octubre). Frecuentación y consumo cultural del Público en Museos: Aportes para repensar las políticas culturales en Buenos Aires. Disponible en: http://www.naya.org.ar/congreso/ponencia3-2.htm

Allard, Michel y Larouche, Marie-Claude. (1994, Octubre). La evaluación de programas de interpretación de la historia destinados a los grupos escolares en los lugares históricos canadienses. Universidad de Québec, Montreal. Para la reunión del ICOM en Cuenca, Ecuador. Canadá. Disponible en: http://www.museums.ca/fr/publications/muse/1994/printemps94/visiteurs.htm 
Amaze Design and The National Park Service. (2007a, February). The National Park Service. Overview of Reactions to Prototypes. Available at: http://www.nps.gov/hfc/pdf/evaluate/eval-afbg-formative.pdf

Amaze Design and The National Park Service. (2007b February). Formative Evaluation of Selecterd Exhibits for the Interpretive Center at the African Burial Ground. Overview of Reactions to Prototypes. Available at: http://www.nps.gov/hfc/pdf/evaluate/eval-afbgformative.pdf

American Association of Museums (AAM). (1991). Professional Standars for the Practice of Visitor Research and Evaluation in Museums. Estados Unidos de América: Committee on Audience Research and Evaluation (CARE).

Anderson, David y Lucas, Keith. (1997). Journal of the Australian Science Education Research, 27(4), 485-495.

Arámubula, Teresa. (1995). Sex Differences in Science Museum Exhibit Attraction. Journal of Research in Science Teaching, 32 (9), 925-938.

Baber, Anne. (2005). Chaining Spaces. Journal of Linguistic Anthropology, 15. Disponible en: www.anthrosource.net

Barreiro, Marcelo. (2009). ¿Why going to a Museum? Motivations and Lifestyle of Museum visitors and non-visitors. Tesis para optar por el grado de Marketing en la Universidad Técnica de Lisboa. España.

Bayo, José. (1987). Percepción, desarrollo cognitivo y artes visuales España: Editorial del hombre: Anthropos.

Bialogorski, Mirta y Cousillas, Ana María. (2002, agosto). Gestión cultural y estudios de Público en el Museo Hernández de la ciudad de Buenos Aires. VII Seminario latinoamericano sobre patrimonio cultural. Disponible en: http://www.geocities.com/jmorentin/gestion.htm.

Bitgood, Stephen. (2010). An Analysis of Visitor Circulation: Movement Patterns and the General Value Principle. Curator, 49 (4), 463-475.

Bitgood, Stephen. (2000). The Role of Attention in Designing Effective Interpretive labels. Journal of Interpretation Research, 5 (2), 31-45.

Bitgood, Steven; Cleghom, Ann; Cota, Amy; Crawford, John M; Patterson, David; Danameyer, Chris y Wetzel, Joseph Associates. (1996). Enhancing the Confrontation Gallery at the Birmingham Civil Rights Institute. Available at: http://informalscience.org/researches/VSA-a0a4k6a 5730.pdf

Bitgood, Stephen. Fall, (1994). Classification of Exhibit Evaluation: How Deep Should Occam's Razzor Cut. Visitor Behavior, IX (3), 8-10. 
Bitgood, Stephen. (1991). Introduction: Visitor Studies in 1990. An Overview of Visitor Studies. Visitor Studies, 3 (1), 7-9.

Bitgood, Stephen; Hines, Joe; Hamberger, Wayne y Ford, William. (1991). Visitor Circulation through a Changing Exhibits Gallery. In A. Benefield, S. Bitgood, \& H. Shettel (Eds.), Visitor Studies: Theory, Research, and Practice, 4. Jacksonville, AL: Center for Social Design.

Blud, Linda. (1990). Social Interaction and Learning Among Family Groups Visiting a Museum. Museum Management and Curatorship, (9). Estados Unidos de Norteamérica.

Bonderup, Niels. (2011). Situational Interest of High School Student Who visit an Aquarium. Science Education, 95 (2), 337-357.

Borum, Minda. (2003, march). Space Comand: sumative evaluation. Available at: http://informalscience.org/download/case studies/report 24.pdf

Borum, Minda. (2002). Object-Based Learning and Family Groups. En: Gaea Leinhardt, Kevin Crowley y Karen Knutson, (eds.), Learning Conversations in Museums. New Jersey: Lawrence Erlbaum Associates, Publishers.

Borum, Minda; Dritsas, Jennifer; Johnson, Julie; Peter, Nigel; Wagner, Kathleen; Fadigan, Kathleen, Jangaard, Arlene; Rodger E. Stroup y Wenger, Angela. (1998). Family Learning in Museums; The PISEC Perspective. Philadelphia-Camden Informal Science Education Collaborative (PISEC). The Franklin Institute. Estados Unidos de América.

Brown, Christine. (1995). Making the most of Family Visits. Museum Management and Curatorship, 14 (1).

Bolaños, María Jesús. (2006). Desorden, diseminación y dudas, el discurso expositivo del Museo en las últimas década". Revista Museos.es, 2, 12-21.

Crowley, Kevin y Galco, Jodi. (2001). Everyday Activity and the Development of Scientific Thinking. En: Kevin Crowley, Christian Schunn y Takeshi Okada. Designing for science: Implications from everyday, classroom, and professional settings. Erlbaum. Estados Unidos de América.

Crowley, Kevin; Callanan, Maureen; Jipson, Jennifer; Galco, Jodi; Topping, Karen y Shrager, Jeff. (2001a, may). Shared Scientific Thinking in Everyday Parent Child Activity. Science Education, 85 (6), 712-732.

Crowley, Kevin; Callanam, Maureen; Tenembaum, Harriet y Allen, Elizabeth. (2001b, may.) Parents Explain More Often to Boys Than to Girls During Shared Scientific Thinking. American Psychological Society, 12 (3), 258-261.Learning Research and Development Center, University of Pittsburgh, and Psychology Department, University of California. United States of America. 
Crowley, Kevin y Callanan, Maureen. (1998). Identifying and Supporting Shared Scientific Reasoning in Parent Child Interactions. Journal of Museum Education, 23, 12-17.

Daniels, Harry. (2003). Vigotsky y la pedagogía. España: Ediciones Paidós Ibérica.

De las Nieves, Alicia, Grandi, María Emilia y Lloret, Florencia. (2002, noviembre). Museos ¿nuevos públicos o nuevas actitudes hacia sus públicos? ICOM. Disponible en: http://www.ilam.org/museos-y-publico/138-museos-inuevos-publicos-o-nuevas-actitudeshacia-sus-publicos.html

Diamond, Judy. (1986). The Behavior of Family Groups in Science Museums. Revista Curator, 29, $139-154$.

Díaz, Carlos. (2002). Visitantes al Museo Nacional de Costa Rica: análisis y captación de público. Costa Rica: Museo Nacional de Costa Rica. Documento interno. Departamento de Proyección Museográfica.

Dierking, Lynn. (2002). The Role of Context in Children's Learning From Objects and Experiences. En Scott Paris (ed.), Perspectives on Object-Centered Learning in Museums.. Lawrence Erlbaum Associates, Publishers. EE.UU.

Dierking, Lynn y Falk, John. (1994). Family Behavior and Learning in Informal Science Settings: A Review of the Research. Science Education, 78.

Ellenbogen, Kirsten. (2002). Museums in Family Life: An Ethnographic Case Study. En: Gaea Leinhardt, Kevin Crowley y Karen Knutson (eds), Learning Conversations in Museums. New Jersey: Lawrence Erlbaum Associates, Publishers.

Everett, Michelle y Barrett, Margareth. (2009). Investigating Sustained visitor/museum Relationships: Employing Narrative Research in the Field of Museum Visitor Studies. Visitor Studies, 12 (1), 2-15.

Fallas, Carmen. (2001, agosto). Encuestas para agencias de viajes. Documento interno Costa Rica: Museos de Banco Central.

García, Néstor. (1991). El consumo cultural en México. Grijalbo-CNCA. México.

García, Ángela. (1988). Didáctica del Museo: el descubrimiento de los objetos. España: Ediciones de la Torre.

Gilbert, John y Stocklmayer, Susan. (2001). The design of Interactive Exhibitis to Promote the Making of Meaning. Museum Management and Curatorship, 19 (1), 41-50.

Gutterman, Sandra; Anijovich, Rivka, y Consentino, Carlos. (2000). La investigación en educación. Didáctica: problemas teóricos y desafíos de la práctica. Argentina: Museo de los Niños Abasto, departamento educativo. Documento interno. 
Guzmán, Carlos. (1995). Políticas culturales y públicos. Disponible en: http://museosdevenezuela.org/documentos/3publicos/museosypublico004(2-1)shtml

Hayward, Jeff. (1992). Exhibit Environments Enhance Educational Effectiveness. Journal of Museum Education, 17 (3).

Hernández, Francesc Xavier y Rubio, Xavier. (2009). Interactividad, didáctica y Museos. Enseñanza de las Ciencias Sociales, 8, 91-96.

Hein, George y Alexander, Mary. (1998). Museums Places of Learning. Estados Unidos de Norte América: American Association of Museums. Education Committee. Technical Information Service.

Hein, George. (2006). John Dewey's "Wholly Original Philosophy" and Its Significance for Museums. Curator, 49 (2), 181-203.

Hein, George. (2004). John Dewey and Museum Education. Curator, 47 (4), 413-427.

Hein, George. (1994). Evaluation of Museum Programmes and Exhibits. The Educational Role of the Museum, 306-312. Rowtledge, Inglaterra.

Hodge, Robert; D'Souza, Wilbert y Riviere, Georges. (1994). The Museum as Communicator: a semiotic analysis of the Western Australian Gallery, Perth. In Eilean Hooper-Greenhill (ed.), The Educational Role of the Museum. British Library Cataloging. England.

Hoffmaister, Jorge. (2001). Museo de los Niños: auditoría servicio al cliente. Trabajo para el curso de Relaciones Públicas Externas; Escuela de Comunicación Colectiva. Universidad de Costa Rica. Documento Inédito.

Jensen, Kari Ann. (2006). Effects Of The Artistic Design of Interpretative Signage On Attracting Power, Holding Time and Memory Recall. Tesis presentada a la Facultad de Humbolt State University como requisito parcial para optar por el grado de Master en Science In Natural Resourses: Planning and Interpretation. Estados Unidos de Norteamérica.

Klein, Hans-Joachim. (1993). Traking Visitor Circulation in Museum Settings. Environment and Behaviour, 25 (6), 782-800.

Kmetz, Debbie. (1993, May). Seeing It With Your Own Eyes. Boletin del Smithsonian Institute, 1 (1). Available at: http://museumstudies.si.edu./bull/may93/kmetz.htm.

Knutson, Karen y Crowley, Kevin. (2010). Connecting with Art: How families talk about Art in a Museum Setting. En: M.K. Stein, L. Kucan (eds.), Instructional Explanations in the Disciplines. EEUU: Springer.

Korenic, Mary. (2002). Visitor Studies: A Museum Educator's Perspective (Chapter 6). Estados Unidos de Norte América: Milwaukee Public Museum. 
Korn, Randi y Associates, Inc. (2003, April). Selma To Montgomery National Historic Trail and Visitor Center. Front-End Evaluation. Amaze Design, Inc. The National Park Service and The Alabama Department of Transportation and Federal Highway Administration. Available at: http://www.nps.gov/hfc/pdf/evaluate/eval-semofrontend.pdf

Korn, Randi y Associates, Inc. (2000). Sumative Evaluation: Executive Summaries, Discussion and Recommendations. The Tech Museum of Innovation. Documento interno. Estados Unidos de Norte América.

Korn, Randi. (1994, March/April). Studying your Visitors: Where to Begin. American Association of State and Local History. Available at: http://museumstudies.si.edu

Korn, Randi y Jones, Johanna. (1998). Go Figure! Evaluating a Math Exhibition. Available at: http://museumstudies.si.edu/

Kotler, Neil y Kotler Philip. (2001). Estrategias y Marketing de Museos. España: Ariel Patrimonio Histórico.

Kuflik, Tsvi; Boger, Zvi y Zancanaro, Massimo. (2009). Analysis and Prediction of Museum Visitors'Behavioral Pattern Types. Haifa. Available at: http://www.cri.haifa.ac.il/files/Minerva\%20Scho\%202009/Analysis\%20and\%20Prediction\% 20of\%20Museum\%20Visitors\%20Behavioral\%20Patterns\%20Types.pdf

Leinhardt, Gaea y Crowley, Kevin. (1998). Museum Learning As Conversational Elaboration: A Proposal to Capture, Code, and Analyze Talk in Museums. Learning Research and Development Center. University of Pittsburgh. Available at: http://mlc.lrdc.pitt.edu/mlc

Leinhardt, Gaea; Crowley, Kevin y Knutson, Karen (eds). (2002). Learning Conversations in Museums. Lawrence Erlbaum Associates, Publishers. University of Pittsburgh. EEUU.

Lewin-Benham, Anne. (1997). Research on Learning in Museums: Three Realities, an Example and a Promise. Journal of Museum Education, 22 (2 and 3), 10-11.

Luján, Manuel y Rodríguez, Keilyn. (2011). El campamento como programa didáctico: El caso de Vacaciones Felices del Museo de los Niños. Revista Actualidades Investigativas en Educación, 11 (1) Instituto de Investigaciones Educativas, UCR. Disponible en: http://revista.inie.ucr.ac.cr/articulos/1-2011/archivos/campamento-programa-didacticolujan.pdf

Lorente, Jesús Pedro. (2006). Nuevas tendencias en teoría museológica: a vueltas con la museología crítica. Revista Museos.es, 2. Ministerio de Cultura de España.

Martinón, Jean Paul. (2006). Museum, Plasticity, Temporality. Museum Management and Curatorship, 21. Disponible en: www.elsevier.com/locate/musmancur 
McClafferty, Terence. (2000). Visitors Use and Understanding of Interactive Exhibitions and Learning of Scientific Concepts. Tesis doctoral. Science and Mathematics Education Center. Curtin University of Technology.

Mortensen, Marianne. (2011). Analysis of the Educational Potential of a Science Museum Learning Environment; Visitor's Experience with and understanding of an Immersion Exhibit. International Journal of Science Education, 33 (4), 517-545.

Museos Banco Central. (1999a.) Análisis y resultados de la encuesta realizada a la exhibición: "Papel moneda: origen, uso y función." Documento interno. Costa Rica.

Museos Banco Central. (1999b.) Análisis y datos comparados de las visitas guiadas a los museos del Banco Central: 1998-1999. Documento interno, Departamento de Educación. Costa Rica.

Pérez, Eloisa. (2000). Estudios de visitantes en Museos: metodología y aplicaciones. España: Edit. Trea.

Pérez, Eloisa. (1998). La evaluación psicológica de los museos y exposiciones: fundamentación teórica y utilidad de los estudios de visitantes. Tesis doctoral. Facultad de Psicología. Universidad Complutense de Madrid.

Pérez, Eloisa. (1995, Julio). El impacto de las exposiciones del Museo Nacional de Ciencias Naturales: 5 años de investigación sobre público. Revista de Museología, 5. Edita Asociación Española de Museología. España.

Psathas, George. (1995). Conversation Analysis: The Study of Talk-in-Interaction. Qualitative Research Methods, 35. EEUU: Sage Publications, Inc.

Pastor, María Inmaculada. (2004). Pedagogía Museística: Nuevas perspectivas y tendencias actuales. España: Editorial Ariel Patrimonio.

Piscitelli, Barbara y Weier, Katrina. (2002). Learning With, Though, and About Art: The Role of Social Interactions. En: Scott Paris (ed.), Perspectives on Object-Centered Learning in Museums. Inglaterra: Edit. LEA.

Pol, Elena y Asensio, Miguel. (1997). ¿Porqué es efectivo un montaje?: Un estudio sobre las teorías de profesionales del Museo. Boletín de la ANABAD, 47 (1), 177-195.

Ramsey, Margareth. (1971). Education and Space in the Museum: a Structural model. University of New Mexico. Tesis doctoral en Educación. EEUU.

Rico, Juan Carlos. (2006). Manual práctico de museología, museografía y técnicas expositivas. España: Silex Ediciones. 
Rix, Chris y McSorley, Jacqueline. (1999). An Investigation into the Role that School-Based Interactive Science Centres may Play in the Education of Primary-Aged Children. International Journal of Science Education, 21 (6), 577-593.

Rodríguez, Keilyn y Vargas, Vanessa. (2009). Análisis del experimento como recurso didáctico en talleres de ciencias: el caso del Museo de los Niños de Costa Rica. Revista Electrónica Actualidades Investigativas en Educación, 9 (1). Universidad de Costa Rica. IINIE. Disponible en: http://revista.inie.ucr.ac.cr/articulos/1-2009/pdf/Museo.pdf

Rodríguez, Keilyn. (2008). La participación guiada de padres y madres con sus hijas o hijos, de I y II Ciclo escolar en la visita familiar al Museo de los Niños de Costa Rica. Tesis sometida a la consideración de la Comisión del Programa de Doctorado en Educación para optar por el grado de Doctora en Educación. Facultad de Educación. Universidad de Costa Rica. Costa Rica.

Rodríguez, Keilyn. (2005). Aporte de la nueva museología española al Museo de los Niños de Costa Rica. Revista Electrónica Actualidades Investigativas en Educación, 5 (2). Universidad de Costa Rica. INIE. Disponible en: http://revista.inie.ucr.ac.cr/articulos/12009/archivos/Museo.pdf

Sabbatini, Marcelo. (2004). Museos y centros de ciencia virtuales. Tesis para optar por el grado de doctor. Universidad de Salamanca, Instituto Universitario de Ciencias de la Educación. España.

Screven, Chan. (1993). Estudios sobre visitantes: en los Estados Unidos, una ciencia en formación. Museum International, 178, XLV (2), 4-12

Shettel, Harris. (2007, August). Evaluation Report Critical Appraisal Bird Visitor Center Exhibit Within a Day's Drive of Millions... National Park Service, Harpers Ferry Center. Available at: http://www.nps.gov/hfc/pdf/evaluate/eval-shen-byrd-summative.pdf

Shettel, Harris. (2004, September). Sequoia National Park Visitor Evaluation Final Report. National Park Service, Harpers Ferry Center. Available at: http://www.nps.gov/hfc/pdf/evaluate/eval-seki-summative.pdf

Shettel, Harris. (2002, March). Remedial Evaluation Study: Focus Group Result. Rock Creek Discovery Center. Rock Creek Park. Available at: http://www.nps.gov/hfc/pdf/evaluate/eval-rocr-summative.pdf

Shettel, Harris. (2001, February). Manzanar: Front-End Evaluation. Focus Group Results. National Park Service. Harpers Ferry Center. Available at: http://www.nps.gov/hfc/pdf/evaluate/eval-manz-frontend.pdf

Schulman, Lee. (1989). Paradigmas y programas de investigación en el estudio de la enseñanza: una perspectiva contemporánea. En: Merlín C. Wittrock (comp.), La investigación de la enseñanza: Enfoques, teorías y métodos. España: Editorial Paidós. 
Serrell, Beverly. (2006). Judging Exhibitions. Estados Unidos: Left Coast Press, Inc.

Serrell, Beverly. (1998). Paying Attention: Visitors and Museums Exhibitions (Professional Practice Series). United States of America: Technical Information Service. American Association of Museums.

Shine, Stephanie and Acosta, Teresa. (2000). Parent-Child Social Play in a Children's Museum. Minneapolis: Estados Unidos de Norteamérica. Disponible en revista electrónica ProQuest.

Smithsonian Institution. (2002, Septiembre,). Exhibitions and Their Audiences: Actual and Potential. Washington, United States of America: Office of Policy and Analysis. Available at: http://museum.studies.si.edu/

Soutiño, Carmen Teresa. (2000). Público y museos. Disponible en: http://museosdevenezuela.org/documentos/3publicos/museosypublico004(2-1)shtml

Tolsa, Georgina; Martínez, Adriana; Redil, Patricia e Higuera, Adriana. (2002). La experiencia confrontativa sujeto-objeto en dos salas del Museo Franz Mayer. Gaceta de Museos. México: CONACULTURA-INAH. ICOM.

Varela, Ximena. (2000). Los museos de América Latina y la nueva administración. Revista de Museología. Madrid, España: Asociación Española de Museólogos.

Vom Lehn, Dirk; Heath, Christian y Hindmarsh, Jon. (2001). Exhibitin interaction: conduct and collaboration in Museum. Symbolic Interaction, 24 (2), 189-216.

Vilnitzky, Laura. (2005). Reporte de avance de tesis doctoral. Istituto di Comunicazione e formazione (ICEF). Facoltá Scienze della Comunicazione. Università della Svizzera italiana (USI). Via Buffi 13 - 6904 Lugano-Svizzera.

Wagnensbert, Jorge. (2004). Principios fundamentales de la museología científica moderna. Revista Museos de México y el Mundo, 1, 22-24.

Wells, Marcela. (2006, January). Formative Evaluation Report For the Naval Live Oaks visitor Centre. Wells Resources, Inc. Available at: http://www.nps.gov/hfc/pdf/evaluate/eval-guis-formative.pdf

Wasserman, Sherri. (2011). Beyond information: Ritual, Relationship and Re-encounter throw Mobile Connectivity. Curator, 54 (1), 11-24.

Wenger, Etienne. (2001). Comunidades de práctica. Aprendizaje, significado e identidad (Colección dirigida por Cesar Coll). España: Paidós. Biblioteca Cogniciòn y desarrollo humano.

Wineman, Jean y Peponis, John. (2010). Constructing Spatial Meaning: Spatial Affordances in Museum Design. Environment and Behaviour, 42 (1), 11-21. 
Doering, Zahaba. (March, 1999). Strangers, Guests or Clients? Visitor Experiences in Museums. Institutional Studies Office. Smithsonian Institute. Available at:http://www.museum.studies.si.edu/http://www.nps.gov/hfc/pdf/evaluate/eval-guisformative.pdf

Zimmerman, Ron; Gross, Michel y Buchholz, Jim. (2008). Creating Exhibits that Expand the Imagination. University of Wisconsin-Stevens Point. Better Visitor Center Workshop. Available http://www.uwsp.edu/CNR/schmeeckle/Interp/Workshops/Wales/Docs/Creating Exhibits.p $\underline{\text { df }}$

Zwinkels, Juul; Oudegeest, Tania y Laterveer, Michaël. (2009). Using Visitor Observation to Evaluate Exhibits at the Rotterdam Zoo Aquarium. Visitor Studies, 12 (1), 65-77. 